\title{
A follow-up study of a large group of children struck by lightning
}

\author{
L M A Silva, ${ }^{1} \mathrm{PhD} ; \mathbf{M}$ A Cooper ${ }^{2,3} \mathrm{MD} ; \mathbf{R}$ Blumenthal, ${ }^{4} \mathrm{MD} ; \mathbf{N}$ Pliskin, ${ }^{5} \mathrm{PhD}$ \\ ${ }^{1}$ Department of Psychiatry, University of Texas-Southwestern, Dallas, Texas, USA \\ ${ }^{2}$ Department of Emergency Medicine, College of Medicine, University of Illinois, Chicago, Ill., USA \\ ${ }^{3}$ African Centres for Lightning and Electromagnetics Network, Makerere University School of Business, Kampala, Uganda \\ ${ }^{4}$ Department of Forensic Sciences, School of Medicine, Faculty of Health Sciences, University of Pretoria, South Africa \\ ${ }^{5}$ Department of Psychiatry, College of Medicine, University of Illinois, Chicago, Ill., USA
}

Corresponding author: $M$ A Cooper (macooper@uic.edu)

Background. On 11 November 1994, 26 preadolescent girls, 2 adult supervisors and 7 dogs were sleeping in a tent in rural South Africa when the tent was struck by lightning. Four of the girls and 4 of the dogs were killed. The 2 adults were unharmed, but all but 3 of the children suffered significant injuries. An article in 2002 detailed the event and examined the medical and psychological changes in the surviving girls.

Objective. To understand the medical and psychological changes secondary to lightning strike years after injury.

Methods. An online questionnaire was prepared that included a checklist of physical and psychological symptoms. Participants were asked to report on both initial and current symptoms. Eleven of the 22 survivors were contacted, and 10 completed the survey.

Results. Participants reported that initial physical symptoms generally resolved over time, with $\sim 10$ - $20 \%$ continuing to experience physical symptoms. Vision problems persisted in $50 \%$ of respondents. Psychological symptoms, overall, had a later onset and were more likely to be chronic or currently experienced. Depression and anxiety, specifically, were higher among the survivors than the reported incidence in South Africa.

Conclusions. Initial and current/chronic physical and psychological symptoms following lightning strike are reported, adding to the body of literature on the long-term after-effects of lightning strike on survivors. A brief discussion on post-traumatic stress disorder symptomatology and post-lightning shock syndrome is provided.

S Afr Med J 2016;106(9):929-932. DOI:10.7196/SAMJ.2016.v106i9.10564

A previous article ${ }^{[1]}$ examined an incident on 11 November 1994, in which 26 preadolescent girls, 2 adult supervisors and 7 dogs were sleeping in a tent in a rural area near Nylstroom (now known as Modimolle) in the Northern Province of South Africa (SA). Four lightning flashes occurred in the vicinity between $2 \mathrm{~h} 00$ am and $2 \mathrm{~h} 30$ am. All were single-stroke negative discharges, ranging from -33 to $-67 \mathrm{kA}$. Four of the girls and 4 of the dogs were killed (Fig. 1). The adults reported no injuries. No follow-up studies have been done to date on such a large group of people, especially children.

The initial report concentrated on physical sequelae such as burns, cataracts and macular holes, skull fractures and tympanic membrane rupture, and did not investigate symptoms of pain, weakness or more subjective clinical findings. The original study was unique because it was one of the first case studies to illustrate the damaging effects of the so-called fifth mechanism of lightning injury, although a number of mechanisms such as sideflash and ground current may have contributed to the injuries. ${ }^{[2]}$ This study investigates the long-term problems that the surviving girls continue to experience as a consequence of the 1994 lightning incident, including neuropsychological issues, mood symptoms and chronic pain. ${ }^{[3,4]}$

The dangers of upward streamers have been relatively well documented. ${ }^{[2]}$ Injury may occur when a victim serves as the conduit for one of the usually multiple upward leaders induced by a downward stepped leader and its field. Upward streamers occur even when there is no attachment between them. While one might think that these upward streamers are weak in energy compared with the full lightning strike, they may carry several hundreds of amperes of current that may be transmitted through or around the victim. Upward streamer injury is probably a much-underestimated mechanism of injury, and may account for as many as $10-15 \%$ of injury cases. ${ }^{[5]}$

Lightning is one of several threats to life and property posed by severe weather conditions. There are up to 100 lightningrelated fatalities annually in SA, and it is probable that at least four or five times as many survivors of lightning strike present for clinical treatment. ${ }^{[6]}$ With the relatively high mortality and morbidity associated with lightning in SA, there has been a need for a followup study on lightning strike victims. In addition, although the complications and long-term sequelae of lightning injury have been described, there have been no long-term follow-up studies done with lightning survivors to delineate the frequency of the sequelae. ${ }^{[3,4]}$

\section{Methods \\ Sample}

The present study examined self-report responses to an online survey collected from survivors of the 1994 lightning strike. Of the 22 surviving young women, contact details could be obtained for only 11 . These were contacted directly by the researchers, with a response rate of $82 \%$. One of the survivors volunteered to attempt to recruit more respondents by using a social media network that some of the survivors used to keep in touch. ${ }^{[7]}$ This yielded one additional response $(N=10)$ (Table 1$)$. The study was approved by institutions in both the USA (Institutional Review Board, University of Illinois at Chicago) and SA (Ethics and Integrity Committee, University of Pretoria). The data were collected with the permission and assistance 


\begin{tabular}{ll} 
Table 1. Demographic information $(\mathbf{N = 1 0})$ \\
\hline Age (years), mean (SD) & $30.4(0.4)$ \\
Race, $n(\%)$ & \\
Caucasian & $7(70)$ \\
African & $1(10)$ \\
Indian & $1(10)$ \\
Chinese & $1(10)$ \\
SD $=$ standard deviation. &
\end{tabular}

of the current headmistress of the primary school the girls had attended at the time of the incident. The previous headmistress, mother of one of the girls fatally injured, was also informed of the study.

\section{Measure}

A three-part questionnaire based on the previous study ${ }^{[1]}$ and pertaining to immediate symptoms following the lightning strike, persisting symptoms and subjective experience (including recalled location in the tent) was administered online. Certain items only relevant to immediate symptoms (e.g. loss of consciousness) were eliminated from the portion of the questionnaire pertaining to persisting symptoms.

\section{Analyses}

Frequencies of immediate and current symptoms were calculated and compared.

\section{Results}

Three participants reported loss of consciousness at the time of the lightning strike, and 6 reported current scars. Participants were asked to recall their position in the tent at the time of the lightning strike to compare reports of the initial injuries reported in the previous study ${ }^{[1]}$ with participants' recollections of their injuries nearly 20 years later. Five girls were quite sure of their positions $(\mathrm{H}, \mathrm{L}, \mathrm{R}, \mathrm{W}, \mathrm{X})$, and some gave details to correct the diagram (Fig. 2) from the original study. ${ }^{[1]}$ Three gave approximate positions (HI, S-U, VW) where they could have been located. The remaining 2 participants were unsure of their position in the tent.

Of the 3 who reported current or chronic mood issues, all (100\%) reported initially feeling 'shocked' or dazed and confusion/ disorientation. Two of the 3 (67\%) reported initial numbness/tingling all over and palpitations/racing heart. Of the 5 who reported no current or chronic mood issues, only $2(40 \%)$ reported feeling 'shock' or dazed and confusion/disorientation. Additionally, 2 experienced loss of consciousness, pain/ burning/stiffness all over, weakness all over,

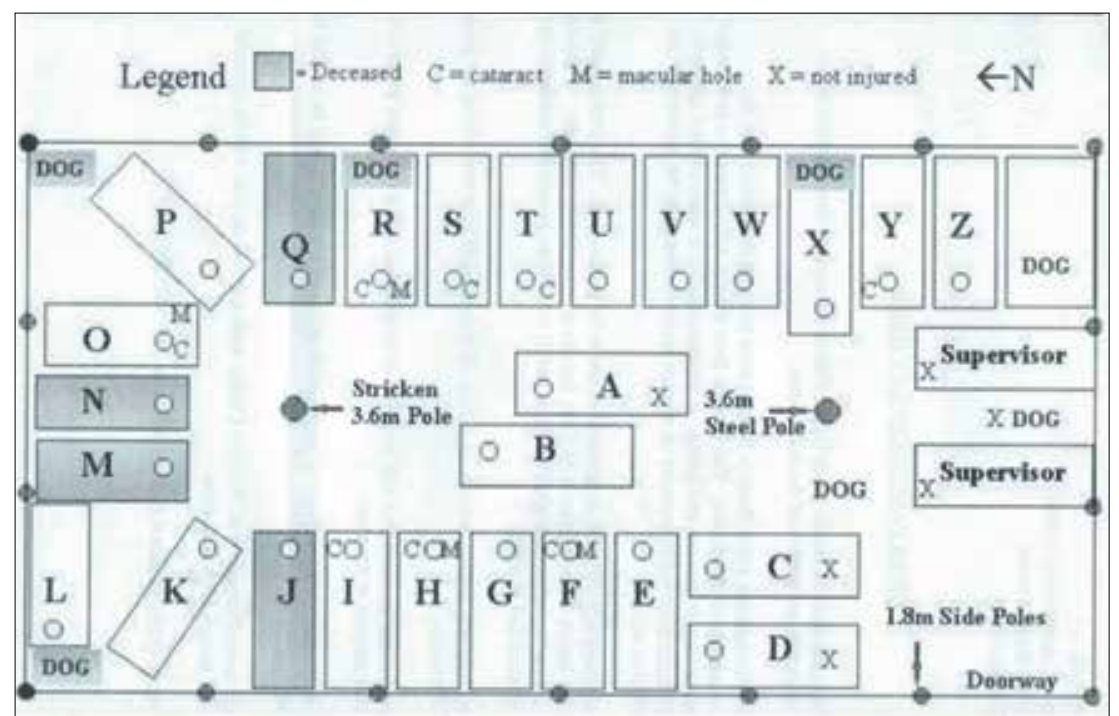

Fig. 1. Figure showing the relative positions of the girls in the $10 \times 5 \mathrm{~m}$ tent from the original report. ${ }^{[1]}$ (Circle = head; shaded $=$ fatally injured; $M=$ macular hole; $C=$ cataract $X=$ not injured.)

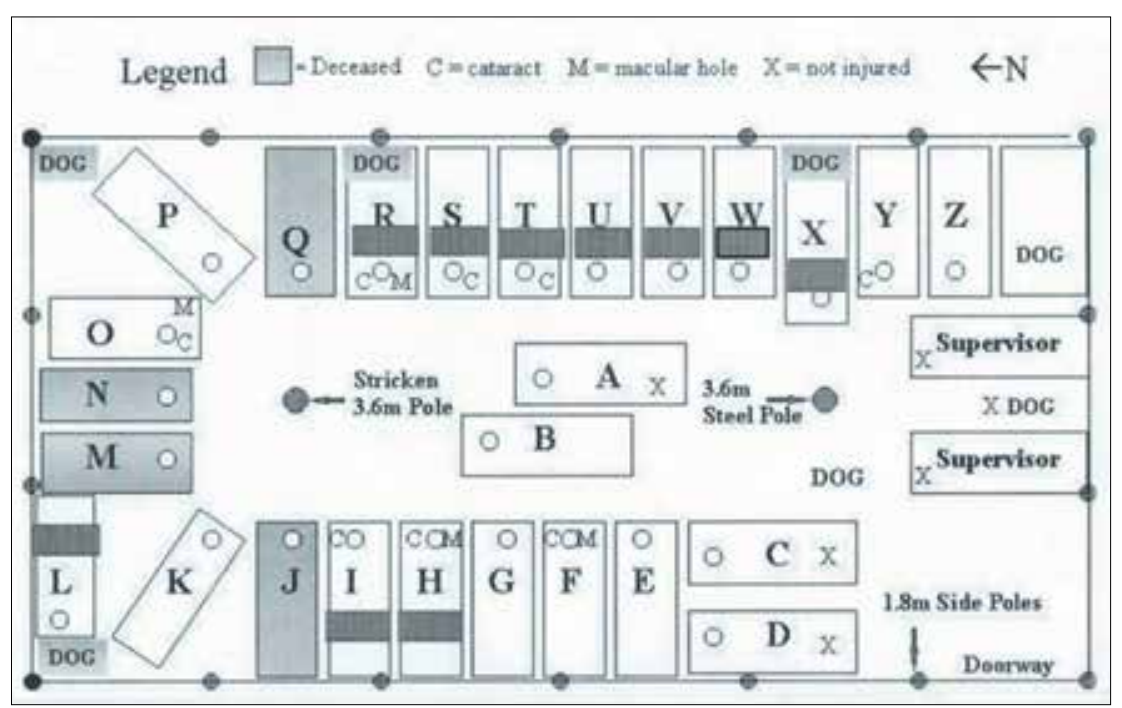

Fig. 2. Positions in the tent recalled by each survivor (indicated by small dark rectangles).

changes in vision, 'giddiness', loss of balance or memory loss. One participant reported no initial symptoms and no current or chronic symptoms. Responses of the other 9 participants are presented in Tables 2 and 3.

\section{Discussion}

While this is admittedly a relatively small study and the results may not be generalisable to a larger population, it is among the first long-term follow-up studies to be done. There was a very high response rate among the survivors who could be contacted.

The most prevalent long-term issue in the present sample was impaired vision. Persistent otological symptoms are reported in the literature. ${ }^{[8]}$ This is important to note, as chronic symptoms experienced by lightning injury survivors are well documented. ${ }^{[3,4]}$ It is worth noting that 5 of the girls reported continuing changes in vision, including one case that was not documented in the original report. This is consistent with ocular pathology post-lighting strike, which is relatively well documented in the literature. ${ }^{[9]}$

Consistent with previous studies, $20 \%$ of participants reported persisting irritability, mood swings, emotional reactivity and feelings of guilt. Depression and anxiety were reported by $30 \%$ of the sample, higher than the reported incidence in SA (20\% per the SA Depression and Anxiety Group (SADAG)). Many of the current and chronic moodrelated changes reported are consistent with post-traumatic stress disorder (PTSD). PTSD is defined as significant distress or functional impairment in response to a traumatic event in the form of a specific set of symptoms: re-experiencing, avoidance, negative cognitions and mood, and heightened arousal. ${ }^{[10]}$ 
Table 2. Reported initial and current/chronic physical symptoms $(N=10)$

\begin{tabular}{|c|c|c|}
\hline Physical symptoms & $\begin{array}{l}\text { Initial } \\
\text { symptoms, } n\end{array}$ & $\begin{array}{l}\text { Chronic/current } \\
\text { symptoms, } n\end{array}$ \\
\hline Deafness, both ears & 1 & 1 \\
\hline Ringing/noises in right ear & 1 & 0 \\
\hline Ringing/noises in both ears & 1 & 0 \\
\hline \multicolumn{3}{|l|}{ Pain/burning/stiffness } \\
\hline Right ear/face/neck & 1 & 0 \\
\hline Right arm/shoulder & 2 & 1 \\
\hline Left arm/shoulder & 1 & 1 \\
\hline Right chest & 1 & 0 \\
\hline Right leg & 1 & 1 \\
\hline Left leg & 2 & 1 \\
\hline Back & 0 & 2 \\
\hline All over & 3 & 0 \\
\hline \multicolumn{3}{|l|}{ Numbness/tingling } \\
\hline Right leg & 1 & 1 \\
\hline Left leg & 1 & 1 \\
\hline All over & 2 & 0 \\
\hline \multicolumn{3}{|l|}{ Weakness } \\
\hline Right leg & 3 & 0 \\
\hline Left leg & 3 & 0 \\
\hline All over & 2 & 0 \\
\hline Changes in vision & 4 & 5 \\
\hline Headache & 2 & 0 \\
\hline Palpitations/racing heart & 2 & 1 \\
\hline Breathing difficulty & 1 & 0 \\
\hline $\begin{array}{l}\text { Giddiness/dizziness/unco- } \\
\text { ordination }\end{array}$ & 2 & 0 \\
\hline Loss of balance & 4 & 1 \\
\hline
\end{tabular}

The results of studies that examine long-term outcomes of PTSD as a result of trauma experienced in childhood or adolescence have been variable, and the populations studied have been heterogeneous in factors such as demographics, type of trauma and treatment history.

However, in studies involving those who experienced a disaster in childhood or adolescence, ongoing PTSD or PTSD-related symptomatology (i.e. fear, depression, etc.) has been shown to persist, sometimes for many years following the event. ${ }^{[11]}$ In a study of schoolchildren involved in a cruise ship collision, $26 \%$ met Diagnostic and Statistical Manual of Mental Disorders, 4th ed. (DSM-IV) criteria for PTSD 5 years following the disaster, and $34 \%$ of those continued to meet criteria up to 8 years following the shipwreck. ${ }^{[11]}$ In a study of child and adolescent survivors of the Buffalo Creek dam collapse disaster, $\sim 25 \%$ met PTSD criteria 14 years later ${ }^{[12]}$ which is generally consistent with the National Comorbidity Survey that demonstrated that approximately one-third of those diagnosed with PTSD fail to recover after many years ${ }^{[13]}$ There has been evidence that levels of depression related to chronic PTSD sustained in adolescence can increase over time ${ }^{[14]}$ Additionally, there is evidence that electrical injury survivors are more likely to experience depression and anxiety concurrently or independent of PTSD symptomatology. ${ }^{[15]}$
Table 3. Reported initial and current/chronic cognitive and emotional symptoms $(N=10)$

\begin{tabular}{lll}
\hline Cognitive/emotional changes & $\begin{array}{l}\text { Initial } \\
\text { symptoms, } \boldsymbol{n}\end{array}$ & $\begin{array}{l}\text { Chronic/current } \\
\text { symptoms, } \boldsymbol{n}\end{array}$ \\
\hline Memory loss/forgetfulness & 4 & 1 \\
Poor concentration & 1 & 1 \\
Confusion/disorientation & 5 & 0 \\
Difficulty following through & 0 & 2 \\
Irritability & 0 & 2 \\
Restlessness & 0 & 1 \\
Temper outbursts & 0 & 1 \\
Mood swings & 0 & 2 \\
Crying/easily upset & 4 & 2 \\
Emotional upset, shaking & 2 & 0 \\
Depression & 0 & 3 \\
Anxiety/tension & 0 & 3 \\
Troubling thoughts, difficult to & 0 & 1 \\
keep out of mind & & \\
Feelings of guilt & 0 & 1 \\
Increased suspiciousness of & 0 & \\
others & &
\end{tabular}

Some of the symptoms reported by the subjects do not fit in with the classic PTSD as described in the DSM. Recently, Andrews proposed DSM criteria for the diagnosis of Post Lightning Shock Syndrome (PLSS) and Post-Electric Shock Syndrome (PESS). These criteria, if adopted, may help to more firmly establish the diagnosis of a syndrome occurring in consequence of a lightning injury.

The fact that the girls still keep in contact with one another via social media demonstrates the impact the 1994 lightning incident had on their respective lives. Given the rapid changes in the communication landscape brought about by participative internet use and social media, it is important to develop a better understanding of these technologies and their impact on health communication. ${ }^{[7]}$

There is a paucity of data on the long-term after-effects of lightning strike on survivors. Therefore, the importance of such a study examining both the physical and psychological sequelae of lightning strike cannot be understated. Furthermore, the long-term dangers of the fifth mechanism of lightning injury have not been widely reported in the literature. This follow-up to the original study, one of the first case studies illustrating the damaging effects of the fifth mechanism, may provide a foundation for further such investigations.

Acknowledgements. The authors would like to thank the current headmistress of St Katherine's School, Mrs Mandy Mitchley, the former headmistress, Mrs Rose Antrobus, and Mrs Mary Salmon, the current school secretary, for their help and assistance.

The original work and meticulous documentation of the lightning incident by Carte et $a l .{ }^{[1]}$ needs to be acknowledged. We would also like to thank Dr Christopher Andrews for sharing his symptoms questionnaire from his 1989 long-term telephone lightning injury survey. The authors would also like to acknowledge and thank the respondents for making themselves available for this study. We are acutely aware of the courage it must have taken to re-confront this tragic incident 19 years later. 
1. Carte AE, Anderson RB, Cooper MA. A large group of children struck by lightning. Ann Emerg Med 2002;39(6):665-670. DOI:10.1067/mem.2002.124438

2. Cooper MA. A fifth mechanism of lightning injury. Acad Emerg Med 2002;9(2):172-174. DOI:10.1197/ aemj.9.2.172

3. Cooper MA. Disability, not death is the main problem. Natl Weather Dig 2001;25(12):43-47.

4. Cherington M. Spectrum of neurologic complications of lightning injuries. Neurorehabilitation 2005;20(1):3-8.

5. Cooper MA, Holle RL. Mechanisms of Lightning Injury Should Affect Lightning Safety Messages International Lightning Detection Conference, Tucson, Arizona. 2010. http://www.vaisala.com/ Vaisala\%20Documents/Scientific\%20papers/11.Cooper,\%20Holle.pdf (accessed 7 June 2015).

6. Blumenthal R, Trengrove E, Jandrell IR, et al. Lightning medicine in South Africa. S Afr Med 2012;102(7):625-626.

Chou WS, Hunt YM, Beckjord EB, et al. Social media use in the United States: Implications for health communication. J Med Internet Res 2009;11(4):e48. DOI:10.2196/jmir.1249

8. Cankaya $\mathrm{H}$, Egeli E Evliyaoglu Z Hearing loss caused by lightning strike: Case report and review of the literature. J Otolayngol 2002;31(3):181-183. DOI:10.2310/7070.2002.10913

9. Dinakaran S, Desai SP, Elsom DM. Ophthalmic manifestations of lightning strikes. Surv Ophthalmol 2002;47(3):292. DOI:10.1016/s0039-6257(02)00281-3
10. American Psychiatric Association. Diagnostic and Statistical Manual of Mental Disorders (4th ed). Washington, DC, USA: American Psychiatric Association, 1994.

1. Yule W, Bolton D, Udwin O, et al. The long-term psychological effects of a disaster experienced in ade , Bolton D, Udwin O, et al. The long-term psychological effects of a disaster experienced in
adolescence: I: The incidence and course of PTSD. J Child Psychology Psychiatry 2002;41(4):503-511. DOI:10.1017/ 00021963099005570

12. Green BL, Lindy JD, Grace MC, et al. Chronic post-traumatic stress disorder and diagnostic comorbidity in a disaster sample. J Nerv Mental Dis 1992;180(12):760-766. DOI:10.1097/00005053199212000-00004

13. Kessler RC, Sonnega A, Bromet E, et al. Post-traumatic stress disorder in the national comorbidity survey. Arch Gen Psych 1995;52(12):1048-1060.

14. Goenjian AK, Walling D, Steinberg AM, et al. A prospective study of posttraumatic stress and depressive reactions among treated and untreated adolescents 5 years after a catastrophic disaster. Am J Psych 2005;162(12):2302-2308. DOI:10.1176/appi.ajp.162.12.2302

15. Ramati A, Rubin LH, Wicklund A, et al. Psychiatric morbidity following electrical injury and its effects on cognitive functioning. Gen Hosp Psychiat 2009;31(4):360-366. DOI:10.1016/j. genhosppsych.2009.03.010

Accepted 31 January 2016. 